\title{
Chapter 11 \\ Education as a Financial Transaction: \\ Contract Employment and Contract \\ Cheating
}

\author{
Katherine Crossman (iD)
}

\begin{abstract}
Over the last decade, high-profile cases of academic misconduct have surfaced across Canada (Eaton, 2020a). I argue that it is systemic issues that contribute to their ubiquity: knowledge is seen as a commodity, transcripts and credentials as products, and students as consumers. As provincial governments in Ontario and Alberta introduce funding models tied to graduate earnings and employment (Anderson, 2020; Weingarten et al., 2019), education becomes a financial transaction and academic integrity is threatened. Credentials hold more value than the process of learning, and when students pay for credentials, it is more palatable to pay for grades. This is exacerbated by a supply and demand for academically dishonest practices. File sharing websites that facilitate cheating are ubiquitous; coursehero.com alone is worth over one billion dollars (Schubarth, 2020). Targeted advertisements for essay mills abound. Meanwhile, academia increasingly relies on the labour of sessionals (Shaker \& Pasma, 2018), who tend to underestimate the scope of misconduct (Hudd et al., 2009) and are less likely to report infractions (Blau et al., 2018). Furthermore, those with graduate degrees are increasing (Wall et al., 2018) while stable academic jobs are fewer (Kezar, 2013). Academics faced with precarious employment often supplement income in what Kezar et al. (2019) refer to as the "gig academy". They are well-positioned to meet the demand for ghost-written papers (Sivasubramaniam et al., 2016). Although many institutions have responded with well-articulated policies and procedures, when entrenched in a system that incentivises and facilitates dishonest practices, they are not lasting solutions to chronic problems.
\end{abstract}

Keywords Academic integrity $\cdot$ Neoliberalism $\cdot$ Contract cheating $\cdot$ Contract employment $\cdot$ Credentialism

\footnotetext{
K. Crossman ( $\bowtie)$

Bow Valley College, Calgary, Canada

S. E. Eaton and J. Christensen Hughes (eds.), Academic Integrity in Canada, 


\section{Background}

Over the last decade, high-profile cases of academic misconduct have surfaced across Canada (Eaton, 2020a) and the globe, implicating individuals in powerful positions, right up to the president of the United States, who was accused of hiring a proxy to sit his SAT exam, securing him entrance into Wharton School of Business (Trump, 2020). Closer to home, recent examples of academic misconduct in the Canadian news include the arrest of an impersonator during an exam (Bains, 2019), faculty degrees rescinded (Graveland, 2018), accusations of bribery in return for grades (Leo, 2017), the revocation of the Order of B.C. in response to a college admissions scandal (CBC News, 2020), and a questionable connection between the Alberta Minister of Advanced Education and a ghost-writing website (Siever, 2020). Although we see these types of cases with frequency in our newsfeeds, it is likely that the scope of academic misconduct is still more ubiquitous and undiscovered.

Post-secondary landscapes have changed since the seminal work of Christensen Hughes and McCabe (2006a, b) about academic misconduct in Canada. I argue that emerging and systemic issues in higher education and society as a whole have contributed to the ubiquity of academic misconduct and how it has shapeshifted in response to new pressures and technologies. A glance at the comments section of any news article about such cases and it is apparent that the public is quick to point fingers at individuals and their perceived moral failings; individuals are viewed to be solely responsible. Instead, in this chapter, I contend that neoliberalist pressures on post-secondary institutions have led to an academic landscape where knowledge is a commodity, transcripts and credentials are products, and students are consumers. This chapter argues that economic and employment precarity among instructors, disenfranchisement of students, and credentialism have created ideal conditions for academically dishonest behaviours, in particular contract cheating.

\section{Education as a Transaction}

Tensions between public education and government funding are not new. Earlier in this millennium, British Columbia faced massive cuts to education budgets under premier Gordon Campbell during a time of economic optimism (Millar, 2008). Years later, in the shadow of the economic downturn, such tensions persist and have heightened. Add to this the global pandemic and a resultant sea change in education, and the future of higher education is murky, with the only certainty being that financial tensions will endure.

In recent years, provincial governments have introduced new funding models tied to graduate earnings and employment (Anderson, 2020). Although delayed in Ontario due to COVID-19 (Friesen, 2020), the province's proposed plan will tie $60 \%$ of higher education funding (some 3 billion Canadian dollars) to a list of 10 metrics by 2024-25; the rate when this plan was released in 2019 was $1.4 \%$ for 
universities and $1.2 \%$ for colleges (Crawley, 2019). According to the Ontario model outlined by the Higher Education Quality Council of Ontario (Weingarten et al., 2019), educational outcomes are measured and quantified by tax-linked data, and faculty are compensated based on discrete research outputs and workloads. The overarching goal of these policies is to produce "outcomes-based funding mechanisms and meaningful, intentional performance agreements between government and providers" (Weingarten et al., 2019). The province of Alberta has proposed a model closely based on Ontario's; in fact, the lead author on the Higher Education Quality Council of Ontario's recommendation is a former University of Calgary president. Unlike Ontario, Alberta plans to push ahead with this proposed funding model despite the global pandemic (Friesen, 2020), as the provincial government focuses on economic recovery. Although these funding models have clear financial foci, what they lack is mention of the intangible benefits of higher education, such as the increase of knowledge or development of character. The gradual shift "from a mission of public knowledge and citizenship to a mission of job training and profitable patents" (Westheimer, 2018, p. 224) is notable.

The past decade has seen a marked shift from publicly-funded education to publicly-aided education (Usher, 2020, p. 33). Since 2008, post-secondary institutions across Canada have become increasingly dependent on tuition fees, the revenue from which doubled in the last 12 years from $\$ 8$ billion to $\$ 16$ billion CAD; much of it comes from international students who pay significantly higher tuition (Usher, 2020). It is unlikely that this recruitment of international students is a viable solution to funding woes, especially in the wake of COVID-19.

Unable to subsist on government funding and domestic student tuition, postsecondary institutions look to alumni and industry partners for donations. This is not specific to Canada; for example, Oxford University in the UK awarded a Chinese diplomat a created and meaningless credential in the hopes of securing donor dollars (Graham-Harrison, 2020). A quick look at almost any campus directory reveals where the money comes from. Buildings and faculties (now known as "schools") are often named for donors. I used to work in the Faculty of Education at the University of Calgary, which later became the Werklund School of Education and is colloquially referred to by faculty, staff, and students as "Werklund". It used to be called "Education."

Funding models based on discrete economic outcomes naturally lead to the unequal distribution of monies in higher education. Programs that demonstrate graduate employability and higher salaries simply receive more financial backing directly from individual donors and indirectly from provincial coffers, as universities direct more resources into programs that are best aligned with funding metrics. This is not limited only to funding, but also to prestige: Forbes ranks MBA programs by graduate salary increases (Financial Times, 2019).

Concomitant with such models of funding is credentialism: positions that previously did not require post-secondary education now demand it, despite unchanged job descriptions and responsibilities (Fuller \& Raman, 2017) and lower graduate earnings (Usher, 2020, p. 67). This phenomenon is also known as "credential creep" or "qualification inflation" and a causal relationship between contract cheating and 
credentialism has been described (e.g., Walker \& Townley, 2012; Bretag et al., 2018). It is also an unsurprising outcome of a job market where increasing numbers of post-secondary graduates are willing to accept jobs for which they had traditionally been over-qualified. As the goal posts have shifted, the number of business and STEM degrees conferred has increased dramatically while the number of humanities degrees has decreased over the last 15 years in the US and Canada (National Centre for Educational Statistics, 2019; Usher 2020), prompting some to call it the "death of the humanities" (i.e., Hanson, 2014). Similarly, business related post-secondary education is now the most popular major in Canada (Statistics Canada, 2017).

The increasing employer demand for higher education credentials has driven more people to turn to post-secondary programs to secure basic stable employment, despite having little interest or confidence in academia (Callahan, 2004). High school graduates realize that the jobs for which they will apply have artificial prerequisites; therefore they may see degrees as impediments standing between them and a living wage. It is only natural that they will try to remove obstacles from or shorten this path. This inevitably leads to what Westheimer (2018) refers to as the "shopping mall university" in which young people look for "the cheapest and fastest means for obtaining the basic skills and certification they need" and "courses not directly related to job training look more and more like useless dust to be eliminated" (p. 227).

Removing such "inefficiencies" from the system should not be the ultimate goal of higher education (Levidow, 2007). The path to deep knowledge is wending, unquantifiable, and inefficient by nature. Funding models that reduce knowledge to a job title or a figure on tax return is fundamentally at odds with institutional mission and value statements that cite the "advancement of learning and the creation and dissemination of knowledge" (McGill University, 2020), "embracing the power of curiosity, and continually seeking and sharing new knowledge" (University of Calgary, 2019), and "the pursuit, preservation, and dissemination of knowledge" (York University, 2020).

Education becomes a farcical transaction where the players pay lip service to the quest for knowledge while engaging in a transaction whereby time and money are exchanged for credentials, which are then exchanged for job opportunities. Research from the UK (Bunce et al., 2017) found that students who take a consumer-oriented approach to education tend to be in STEM fields of study, grade focused, and feepaying (as opposed to students with scholarships or external funding). The current educational climate rewards all of these tendencies. The researchers found that such students were more likely to believe that grades should be assigned in exchange for tuition. In this scenario, grades and credentials are equated with currency: students are paid in points (Cleminshaw, 2019) in return for educational goods (assignments) and services (participation). When grades are akin to currency (Beatty, 2017), I argue that it becomes more acceptable to pay for them; for example, students who believe they are owed a certain grade because they have paid for it are more likely to exchange other currencies (money) for goods (ghost-written papers) and services (impersonation during an exam). This transactional model is exacerbated by both supply and demand for academically dishonest practices in general and contract cheating in particular. Contract cheating refers to the practice of students engaging 
in a transaction to have their schoolwork completed by a third party (Lancaster \& Clarke, 2008). This typically involves the exchange of money, but can also include bartering.

\section{Supply and Demand}

As described earlier in this chapter, as more jobs require post-secondary education, the number of Canadians with university degrees has steadily increased over the last decades (Statistics Canada, 2017), and students are opting to enrol in more professional and career-focussed programs such as Business (Usher, 2020). One side effect of this is that, rather than a quest for knowledge, university has become a quest for a credential and an obstacle to be overcome. Students recognize this; they pay fees that have increased at rates that outstrip inflation (Usher, 2020) only to be stuffed together in huge theatre style classrooms and large online classes. They know they are being short changed and feel disenfranchised from universities; research has demonstrated that student dissatisfaction with their learning environment is a factor in contract cheating (Bretag et al., 2018).

\section{Contract Instructors and Students}

Meanwhile, increasing reliance on sessional labour in academia is a global phenomenon that is also occurring in Canada (Shaker \& Pasma, 2018); these are also called contract or adjunct instructors, who teach under semesterly contracts. Although some sessional instructors in fields like law or medicine may be wellemployed professionals, the vast majority of sessionals patch together small contracts to put food on their tables or pay off their student loans. They have no guarantee of continued employment beyond their contract and often receive meagre pay and no benefits. Although wages vary, \$5000 CAD is not unusual, although $\$ 6000-7000$ is more typical, depending on the institution and the instructor's place on the pay scale (Canadian Association of University Teachers, 2017), meaning that even with a full teaching load many sessionals live in poverty. In a national survey, sessional instructors rank job security is the most important concern followed closely by pay; over half of respondents reported that their ability to make long term plans to buy a home or have children has been negatively impacted by their job precarity (Foster \& Birdsell Bauer, 2018).

Sessionals' precarious employment is compounded by the transactional nature of education and student disenfranchisement discussed earlier in this chapter. Threads on Reddit and online platforms for rating instructors commonly refer to how easy a course is, directing and encouraging students to choose courses based on the likelihood of getting a high mark for little work. They can review individual instructors on websites like Rate My Professor, much like they would review a pair of shoes 
they bought or meal they had. Likewise, institutional student evaluations, which are known to be flawed (Boring et al., 2016), are used as indicators of teaching efficacy and can impact a sessional instructor's chance of being rehired, although at least one Canadian institution has prohibited the use of student evaluations as factors influencing hiring and tenure (Farr, 2018). This system sets the stage for a consumer-oriented approach to education, where the customer is always right, even when they are doing wrong. When it comes to academic integrity, research has shown that sessional instructors tend to underestimate the scope of misconduct (Hudd et al., 2009) and are less likely to report infractions (Blau et al., 2018). It is possible that one reason for this reluctance to report is the precarious nature of their employment (Eaton, 2020c).

In fact, although sessional instructors are less likely to report academic misconduct, they are more likely to encounter it. It is sessionals who most often teach courses such as general writing and communications courses (Childress, 2019) that are taken by the majority of students across disciplines. These courses are typically large and often online, and the "large and growing workloads of many academics" is suggested by Walker \& Townley (2012, p. 36) as causal factor in contract cheating. I recently taught a writing course that is taken by over 2000 students annually, in cohorts of 60 students. With no teaching assistants, the marking itself was punishing, but add to this communicating with students, preparing materials, and creating assignments, and instructors are left facing a choice "to a. teach for an embarrassingly small hourly rate, b. try to make their teaching something simpler and less time intensive, or c. not teach at all" (Childress, 2019, p. 277). Although there are many recommendations to prevent contract cheating and other forms of academic misconduct, such as changing assignments, alternative assessments, and individual tasks, they are often impractical given current workloads or curricular requirements. The COVID-19 pandemic and the subsequent transition to distance learning has exacerbated this.

The task of effectively teaching and assessing such large numbers of students is an almost impossible one without teaching assistance. Students may rightly feel unsupported and unheard. How can they all get individual attention and assistance when their instructor is over-extended? Certainly, there are proactive students that keep up with the materials and seek assistance of their own volition. But what happens to the students that cannot flag their struggles or articulate their needs to their instructor? With such large classes, especially in remote environments, it is not possible for instructors to know every individual student's writing style and to engage in the individual communication that is necessary to flagging many student issues. It is no surprise that private companies have stepped in to fill the vacuum of faculty and institutional support and mentorship by offering contract cheating services.

\section{Students and Contract Cheating}

In response to what Kaktiņš (2018, p. 272) refers to as the "fractured set of academic norms that have arisen in response to the new academic environment," students are 
often targeted by savvy companies. Advertisements for ghost-written papers and commissioned assignments are commonplace on campus bulletin boards and social media sites like Reddit and Instagram. Many contract cheating companies market to international students in other languages (Kaktinš̌, 2018; Eaton \& Dressler, 2019) and use deceitful techniques such as blackmail or extortion to threaten students who have purchased work (Sutherland-Smith \& Dullagan, 2019). Recent large-scale research out of Swansea (Newton, 2018), demonstrated not only that contract cheating has increased rapidly in recent years, but also that as many as one in seven (or a mindboggling 31 million students globally) have purchased assignments.

Besides purchasing assignments, students often use both formal and informal file sharing sites to share assignments and documents with other students. Like contract cheating, business is booming: Chegg is valued at over 12 billion US dollars, and its valuation increased threefold during the COVID-19 pandemic (Adams, 2021). Coursehero.com was worth over one billion dollars prior to the pandemic (Schubarth, 2020). This site purports to eschew plagiarism and academic misconduct (Course Hero, 2021) while supporting students, and the company has worked hard to create a brand that appears legitimate, even sponsoring educational events for faculty members (Course Hero, 2020). In reality, the company pays students to share their notes, assignments, and class files. Students can be paid with currency, or upload documents in return for access to other documents. Other, less formal ways of sharing assignments are also commonplace, with students sharing materials (i.e., lab reports, previous assignments, exam questions) within learning platforms that encourage collaboration and ePortfolios (Bollinger \& Shepherd, 2010). In some cases, faculty encourage the sharing of previous materials such as exams or student collaboration on assignments, but much of what is uploaded onto file-sharing websites is done without instructor permission or knowledge and is used with the intention to misattribute work (Rogerson \& Basanta, 2016). I believe that the lack of transparency and consistency among classes contributes to confusion about file sharing and file sharing companies capitalize on this opaqueness.

\section{Contract Instructors and Contract Cheating}

The services outlined above are borne of both supply and demand. It is relatively easy for an organization to compile a database of assignments by working with file sharing sites. Likewise, as graduate degree holders increase (Wall et al., 2018) and stable academic jobs decline (Kezar, 2013), those on the margins of academia, such as sessional instructors, are faced with precarious employment and often supplement income in what Kezar et al. (2019) refer to as the "gig academy." The precarity and scarcity of academic employment is expected to persist in Canada; Alberta's Occupational Outlook (Labour and Immigration, Government of Alberta, 2019) predicts a consistent and large surplus of job seekers compared to job openings for university professors and lecturers, with 874 fewer jobs than seekers predicted by 2028 in Alberta; for reference, the imbalance is 277 for 2020; these predictions were 
published in 2019 prior to the COVID-19 pandemic, and it is not clear how or if the pandemic will impact these forecasts. These academic job seekers are well-positioned to meet the demand for ghost-written papers (Sivasubramaniam et al., 2016). Much lower cost ghost writing is done overseas, particularly in Kenya, but former academics or unemployed academics have also been shown to produce commissioned assignments (Lancaster, 2019). Little research exists about this phenomenon because it is such a well-guarded industry (Lancaster, 2019).

One of the largest contract-cheating websites is exemplary of the issues discussed in this chapter; it is also the one implicated in the recent story that leaked wherein a ghost-writer's profile name and educational history shared many similarities with Alberta's minister of Advanced Education, Demetrios Nicolaides (Siever, 2020), although it is extremely unlikely he was actually the profile owner (Eaton, 2020b). This website's main commodities are custom essays written by "current and former academics... spit out or spit on by the system, [who] have become virtual mercenaries." (Unemployedprofessors.com, 2021b).

The FAQ section of this website further states that it is not illegal because the essay has been purchased and copyright transferred, so the customer can do whatever they want with it, and "that's the beauty of capitalism, baby!" Further down the page, the FAQ admits that it's "incredibly" unethical to purchase papers, but it is justified "because the academic system is already so corrupt" (Unemployed Professors, 2021a). As of February, 2021, this company claims to have completed 133,461 projects. I was a long-time sessional instructor with patchy employment and have also had targeted ads for this company pop up in my social media feeds.

This perfect storm of academic dishonesty is disheartening for those of us that value education and the creation of knowledge. Academia today has created a breeding ground for this situation-students who need university credentials for job opportunities but see the process of getting them as an obstacle to overcome, instructors that are overwhelmed and unable to give students the support and feedback necessary to facilitate deep learning, and an extremely competitive job market where graduate degree holders and those with academic writing skills find themselves unable to earn a living wage through traditional academic employment. So, what can be done, and how do we move forward? The next section outlines challenges and opportunities.

\section{What to Do?}

Although many institutions have responded with well-articulated policies and procedures, when entrenched in a system that incentivises and facilitates dishonest practices and situates academic integrity as an individual and moral issue, they are not lasting solutions to chronic problems. Similarly, in medicine, painkillers can make symptoms more bearable, but do little to treat the cause of an illness. Only by identifying and addressing the underlying factors that give rise to the symptoms will a truly effective treatment be possible. 
Many go-to responses like workshops, punishments, and policy updates dull the pain of the academic integrity crisis but may also obscure or even exacerbate problems. For example, students may find themselves looking to policies, workshop information, or technological innovations like text matching software for loopholes or ways to hide dishonest practices. Instead, detailed and realistic policies, sound pedagogy, and educational opportunities for campus community members need to be seen for what they are: ways to enhance treatment and improve outcomes, but only when used thoughtfully and in conjunction with other more lasting measures. Otherwise, they are little more than palliative approaches. The following paragraphs outline areas in which changes need to take place in funding, grading, credentialing, and hiring. These are not easy solutions and they all entail a widespread and fundamental shift in approaches to higher education.

Discrete measurements like GPAs or letter grades are known to be ineffective for providing feedback that encourages learning. Students often look at the grade assigned for information about their work rather than instructor feedback about their work. Studies show (Harrison et al., 2015) that when grades are not included in the feedback, students are more likely to take it up. Grades motivate learners to meet a goal rather than benefit from the process of striving for that goal. One approach is to deemphasize grades or implement "ungrading" (Blum, 2020) to allow students and instructors the space to focus on improvement and learning rather than assigning grades. Grades are entrenched in the educational system, but instructors, administrators, and learners would be wise to question their wholesale value.

Similarly, funding models that look towards discrete measures like graduation and earnings should also be pushed back on. During a time when provincial governments in Canada build a system that favours private education and fosters a system where the privileged pay for credentials in order to maintain their privilege- those without the ability to pay will not have the opportunity to receive an education. Those of us that recognize the value of education as an opportunity to construct knowledge need to be vocal in our protests against models that reduce the value of education to a dollar figure.

Credential inflation also needs to be addressed. In many cases, university education is not necessary. Colleges and technical schools are better positioned to meet the needs of those who are looking for vocational programs. At the same time, colleges should focus on their mandate to provide students with career-track education or an alternative path to university. There has been a recent push in Ontario (Davidson \& Ruparell, 2020) toward colleges granting degrees, while universities may find themselves offering career-track programs to placate funders and secure industry donors, both likely in a bid to compete for limited funds. In the same vein, employers need to recognize that a bachelor's degree is not a proxy for a better employee in many professions and should use other metrics when hiring.

Finally, the hiring practices in academia need to be addressed. It is unfair to those with advanced degrees to be treated as second class citizens, toiling away long hours in precarious, poorly remunerated work. It is unjust for sessional instructors who often find themselves with heavier workloads than their tenure track colleagues, while earning half (or less) their wages. To a lesser extent, it is unjust to teaching 
faculty who are officially hired to focus on instruction, while in practice are expected to engage in research and secure funding, all while teaching a heavier course load and earning a lower salary than their academic track counterparts. Sessionals in particular are often assigned large classes with heavy marking loads. A fairer redistribution of workloads and more equitable remuneration are crucial to addressing academic misconduct. Childress (2019), in his critique of contract employment in American academia, puts forth principles for post-secondary institutions and notes that a worthy institution ought to "foster and to respect its web of relationships. It is a culture shaped and steered by its faculty. It places everyone into a place of continual learning. It asks for regular public demonstration of that learning" he goes on to note that such an environment "would make contingency unthinkable" (p. 154).

I believe that in largely abandoning traditional grading and assessment practices, pushing back on metric-based funding models, reconsidering hiring practices and requisite credentials in industry, and making equitable hiring practices of faculty, academic dishonesty would also be unthinkable in the vast majority of cases. I recognize that these suggestions will be seen as unrealistic by administrators, but they are necessary if the academic integrity problems post-secondary institutions currently face are to be adequately addressed. Surely this would lead to decreased enrollment and revenue, but it would also lead to smaller classes, better pedagogy, knowledge creation, and it would allow universities to truly enact their value and mission statements.

The COVID-19 pandemic has demonstrated the vulnerabilities of the current higher education environment. As classes have moved online, the burden of responsive pedagogy has been revealed. When it was mostly sessionals teaching large online classes without teaching assistance, these concerns fell on deaf ears. Now that many tenure track faculty without fear of keeping their jobs find themselves teaching these classes, they are more able to speak out against the problems in the system. Likewise, students find themselves upset at paying the same tuition while purportedly receiving fewer benefits (Anthistle, 2020); however, academically speaking, little has changed. What students are not benefitting from in the time of the pandemic are the extracurriculars that have become part and parcel of university study. Only time will tell what the long-term impacts of the pandemic will be on higher education, but it has provided a good litmus test of problems that permeate the system.

It is clear that there are no easy solutions. Academic misconduct cannot be willed, punished, or defined away. It is borne of an academic environment steeped in neoliberal policies and funded by those with non-academic interests. It is unrealistic to expect that anything other than a sea change will have a lasting impact on academic integrity. All of us with a vested interest in ethical, just, and intelligent communities in academia and beyond need to recognize and take action against the toxic environment that perpetuates layers of unethical behaviour. It is my hope that the fissures in academia that the pandemic has revealed will catalyze a fundamental restructuring of academia where academic integrity will be the norm. 


\section{References}

Adams, S. (2021). This $\$ 12$ billion dollar company is getting rich off students cheating their way through Covid. Forbes Magazine. https://www.forbes.com/sites/susanadams/2021/01/28/this12-billion-company-is-getting-rich-off-students-cheating-their-way-through-covid/?sh=6e $5 \mathrm{~d} 62$ $79363 f$

Anderson, D. (2020). Alberta post secondary funding will be tied to performance. CBC News. https:// www.cbc.ca/news/canada/calgary/alberta-post-secondary-performance-funding- 1.5433433

Anthistle, M. (2020). Coronavirus: Ontario students frustrated by full tuition fees for online classes. Global News. https://globalnews.ca/news/7298255/coronavirus-ontario-post-secondary-tuitionfees/

Bains, M. (2019). Woman allegedly paid to take exam arrested at SFU. CBC News. https://www. cbc.ca/news/canada/british-columbia/burnaby-rcmp-investigate-after-sfu-catches-alleged-paidtest-taker- 1.5400400

Beatty, J. E. (2017). Grades as money and the role of the market metaphor in management education. Academy of Management Learning \& Education, 3(2), 187-196.

Blau, G., Szewczuk, R., Fitzgerald, J., Paris, D. A., \& Guglielmo, M. (2018). Comparing business school faculty classification for perceptions of student cheating. Journal of Academic Ethics, 16(4), 301-315. https://doi.org/10.1007/s10805-018-9315-4

Blum, S. D. (Ed.). (2020). Ungrading: Why rating students undermines learning (and what to do instead). Morgantown, WV: West Virginia University Press.

Bolliger, D. U., \& Shepherd, C. E. (2010). Student perceptions of ePortfolio integration in online courses. Distance Education, 31(3), 295-314.

Boring, A., Ottoboni, K., \& Stark, P. (2016). Student evaluations of teaching (mostly) do not measure teaching effectiveness. Science Open Research. Retrieved from https://www.scienc eopen.com/document_file/25ff22be-8a1b-4c97-9d88-084c8d98187a/ScienceOpen/3507_XE66 80747344554310733.pdf

Bretag, T., Harper, R., Burton, M., Ellis, C., Newton, P., van Haeringen, K., Saddiqui, S., \& Rozenbuerg, R. (2018). Contract cheating and assessment design: Exploring the relationship. Assessment \& Evaluation in Higher Education, 44(5), 676-691. https://doi.org/10.1080/02602938.2018.152 7892

Bunce, L., Baird, A., \& Jones, S. E. (2017). The student-as-consumer approach in higher education and its effects on academic performance. Studies in Higher Education, 42(11), 1958-1978.

Callahan, D. (2004). The cheating culture: Why more Americans are doing wrong to get ahead. New York: Harcourt Inc.

Canadian Association of University Teachers. (2017). CAUT Facts \& Figures. https://www.caut.ca/ docs/default-source/Mailings-2017/caut---facts-and-figures-(2017-01).pdf?sfvrsn=0

Childress, H. (2019). The adjunct underclass: How America's colleges betrayed their faculty, their students, and their mission. Chicago: University of Chicago Press.

Christensen Hughes, J. M., \& McCabe, D. L. (2006a). Academic misconduct within higher education in Canada. The Canadian Journal of Higher Education, 36(2), 1-21. http://journals.sfu.ca/cjhe/ index.php/cjhe/article/view/183537/183482

Christensen Hughes, J. M., \& McCabe, D. L. (2006b). Understanding academic misconduct. Canadian Journal of Higher Education, 36(1), 49-63. https://journals.sfu.ca/cjhe/index.php/cjhe/art icle/view/183525

Cleminshaw, A. (2019). Grades as currency or how many points is that worth? Redesigning High School. https://redesigningschool.org/grades-as-currency-or-how-many-points-is-that-worth/

Crawley, M. (2019). How the Ford government will decide on university, college funding. CBC News. https://www.cbc.ca/news/canada/toronto/ontario-doug-ford-university-college-postsecondary-grants-1.5121844

Davidson, M. \& Ruparell, S. (2020). The future of Ontario's workers. Strategycorp Institute of Public Policy and Economy. https://strategycorp.com/wp-content/uploads/2020/06/Colleges-Ont ario-The-Future-of-Ontarios-Workers-White-Paper-June-2020.pdf 
Eaton, S. E. (2020a). An inquiry into major academic integrity violations in Canada: 2010-2019. Calgary, AB: University of Calgary. http://hdl.handle.net/1880/111483

Eaton, S. E. (2020b). The intersection of contract academic work and contract cheating: Policy brief. Calgary, Canada: University of Calgary. http://hdl.handle.net/1880/112662

Eaton, S.E. (2020c). Is the Hon. Demetrios Nicolaides, Alberta Minister of Advanced Education involved with contract cheating? Teaching, learning and leadership: A blog for educators, researchers and other thinkers. https://drsaraheaton.wordpress.com/2020/08/15/is-the-hon-dem etrios-nicolaides-alberta-minister-of-advanced-education-involved-with-contract-cheating/

Eaton, S.E. \& Dressler, R. (2019). Multilingual essay mills: Implications for second language teaching and learning. Notos, 14(2), 3-14. http://hdl.handle.net/1880/110695

Farr, M. (2018). Arbitration decisions on student evaluations of teaching applauded by faculty. University Affairs. https://www.universityaffairs.ca/news/news-article/arbitration-decision-onstudent-evaluations-of-teaching-applauded-by-faculty/

Foster, K. \& Birdsell Bauer, L. (2018). Out of the shadows: Experiences of contract academic staff. Canadian Association of University Teachers. https://www.caut.ca/sites/default/files/cas_report. pdf

Friesen, J. (2020). Ontario shelves plan for performance-based postsecondary funding, while Alberta pushes ahead. The Globe and Mail. https://www.theglobeandmail.com/canada/article-ontario-she lves-plan-for-performance-based-postsecondary-funding/

Fuller, J. B., \& Raman, M. (2017). Dismissed by degrees: How degree inflation is undermining US competitiveness and hurting America's middle class. Published by Accenture, Grads of Life, Harvard Business School.

Graham-Harrison, E. (2020). How fake award for a tycoon left oxford university open to Chinese influence. The Guardian. https://www.theguardian.com/education/2020/aug/16/howfake-award-for-a-tycoon-left-oxford-university-open-to-chinese-influence

Graveland, B. (2018). Judge upholds university's right to rescind master's degree over plagiarism. The Canadian Press. https://nationalpost.com/pmn/news-pmn/canada-news-pmn/judge-upholdsuniversitys-right-to-rescind-masters-degree-over-plagiarism

Hanson, V.D. (2014). The death of the humanities. Hoover Institution. https://www.hoover.org/res earch/death-humanities

Harrison, C. J., Könings, K. D., Schuwirth, L., Wass, V., \& van der Vleuten, C. (2015). Barriers to the uptake and use of feedback in the context of summative assessment. Advances in Health Sciences Education, 20(1), 229-245.

Course Hero. (2020). Course Hero Virtual Education Summit '20. Course Hero. Retrieved February 21, 2021, from https://events.coursehero.com/education-summit/home

Course Hero. (2021). Academic integrity policies. Course Hero. Retrieved February 21, 2021, from https://www.coursehero.com/academic-integrity-policies/

Hudd, S., Apgar, C., Bronson, E. F., \& Gravois Lee, R. (2009). Creating a campus culture of integrity: Comparing the perspectives of full- and part-time faculty. The Journal of Higher Education, 80(2), 146-177. https://doi.org/10.1353/jhe.0.0039

Kaktinšs, L. (2018). Contract cheating advertisements: What they tell us about international students' attitudes to academic integrity. Ethics and Education, 13(2), 268-284.

Kezar, A. (2013). Examining non-tenure track faculty perceptions of how departmental policies and practices shape their performance and ability to create student learning at four-year institutions. Research in Higher Education, 54(5), 571-598. https://doi.org/10.1007/s11162-013-9288-5

Kezar, A., DePaola, T., \& Scott, D. T. (2019). The gig academy: Mapping labor in the neoliberal university.. Baltimore, U.S: Johns Hopkins University Press.

Lancaster, T. (2019). Profiling the international academic ghost writers who are providing low-cost essays and assignments for the contract cheating industry. Journal of Information, Communication and Ethics in Society, 17(1), 72-86. https://doi.org/10.1108/JICES-04-2018-0040

Lancaster, T., \& Clarke, R. (2008). The phenomena of contract cheating. In Student plagiarism in an online world: Problems and solutions (pp. 144-159). Pennsylvania, U.S: IGI Global. 
Labour and Immigration, Government of Alberta. (2019). Alberta's occupational outlook 20192028. https://open.alberta.ca/dataset/8987e228-9ffa-4a2e-9f79-a9b869df2ccb/resource/502 659ff-47fb-4ce3-94db-6a0c2f1f722c/download/lbr-albertas-occupational-outlook-2019-2028. pdf

Leo, G. (2017). U of R engineering profs warned about teaching assistants taking bribes to increase grades. CBC News. https://www.cbc.ca/news/canada/saskatchewan/unviersity-of-regina-engine ering-teaching-assistants-1.4369110

Levidow, L. (2007). Marketizing higher education: Neoliberal strategies and counter-strategies. In E. Wayne Ross \& R. Gibson (Eds) Neoliberalism and Educational Reform (pp. 237-256). New York: Hampton Press Inc.

McGill University. (2020). McGill University mission statement and principles. https://www.mcg ill.ca/secretariat/mission\#: :text=McGill\%20University\%20Mission\%20Statement $\% 20$ and $\%$ 20Principles.\%20MISSION.\%20The, international\%20standards $\% 2$ C $\% 20$ and $\% 20$ by $\% 20$ prov iding\%20service\%20to\%20society

Millar, E. (2008). BC's cuts to universities, colleges much more than reported. MacLean's. https:// www.macleans.ca/education/uniandcollege/campbell-govs-cuts-to-unis-colleges-much-morethan-reported/

National Center for Educational Statistics. (2019). Fast facts: Most popular majors. NCES. https:// nces.ed.gov/fastfacts/display.asp?id=37

CBC News. (2020). David Sidoo stripped of order of B.C. over college admissions scandal. CBC News. https://www.cbc.ca/news/canada/british-columbia/david-sidoo-order-bc-col lege-admissions-scandal-1.5610450

Newton, P. M. (2018). How common is commercial contract cheating in higher education and is it increasing? A Systematic Review. Frontiers in Education, 3, 67. https://doi.org/10.3389/feduc. 2018.00067

Rogerson, A. M., \& Basanta, G. (2016). Peer-to-peer file sharing and academic integrity in the internet age. In Handbook of academic integrity (pp. 273-285).

Schubarth, C. (2020). The funded: Silicon Valley's newest unicorn flew in under the radar. Silicon Valley Business Insider. https://www.bizjournals.com/sanjose/news/2020/02/12/the-funded-sil icon-valleys-newest-unicorn-flew-in.html

Shaker, C. \& Pasma, E. (2018). Contract U: Contract faculty appointments at Canadian universities. Canadian Centre for Policy Alternatives. https://www.policyalternatives.ca/publications/reports/ contract-u

Siever, K. (2020). Anyone know if this is the same Demetrios Nicolaides as @ demetriosnAB? How many people with PhD's can there be with that name. Apparently, an MLA salary must not be enough if you have to write essays on the side for people. Weird. \#ableg \#abpoli https://unempl oyedprofessors.com/ProfessorProfile.aspx?ID=963 [Tweet]. Twitter. https://twitter.com/kim_sie ver/status/1294393014333259776

Sivasubramaniam, S., Kostelidou, K., \& Ramachandran, S. (2016). A close encounter with ghostwriters: An initial exploration study on background, strategies and attitudes of independent essay providers. International Journal for Educational Integrity, 12(1), 1. https://doi.org/10.1007/s40 979-016-0007-9

Statistics Canada. (2017). Education in Canada: Key results from the 2016 census. https://www 150.statcan.gc.ca/n1/daily-quotidien/171129/dq171129a-eng.htm

Sutherland-Smith, W., \& Dullaghan, K. (2019). You don't always get what you pay for: User experiences of engaging with contract cheating sites. Assessment \& Evaluation in Higher Education, 44(8), 1148-1162.

Financial Times. (2019). Global MBA Rankings, 2019. Business Education. http://rankings.ft.com/ businessschoolrankings/global-mba-ranking-2019

Trump, M. (2020). Too much and never enough: How my family created the world's most dangerous man. United States: Simon \& Schuster.

Unemployedprofessors.com (2021a). About Us. Retrieved February 21, 2021, from https://unempl oyedprofessors.com/AboutUs.aspx 
Unemployedprofessors.com. (2021b). FAQ. Retrieved February 21, 2021, from https://unemploye dprofessors.com/Faq.aspx

University of Calgary. (2019). Eyes High Strategy 2017-2022. https://www.ucalgary.ca/live-d7-uca lgary-site/sites/default/files/ucgy/groups/Marketing/17-UNV-016-Eyes\%20High\%20strategy\% 20document-digital-FINAL.pdf

Usher, A., (2020). The state of postsecondary education in Canada, 2020. Toronto: Higher Education Strategy Associates. https://higheredstrategy.com/the-state-of-postsecondary-education-incanada-2/

Walker, M., \& Townley, C. (2012). Contract cheating: A new challenge for academic honesty? Journal of Academic Ethics, 10(1), 27-44. https://doi.org/10.1007/s10805-012-9150-y.

Wall, K., Zhao, J., Ferguson, S-J., \& Rodriguez, C. (2018). Results from the 2016 Census: Is field of study a factor in the payoff of a graduate degree? Insights on Canadian Society. https://www 150.statcan.gc.ca/n1/pub/75-006-x/2018001/article/54978-eng.htm

Weingarten, H.P., Hicks, M., Kaufman, A., Chatoor, K., MacKay, E. \& Pichette, J. (2019). Postsecondary education metrics for the 21st century. Toronto: Higher Education Quality Council of Ontario. http://www.heqco.ca/SiteCollectionDocuments/Formatted\%20Metrics\% 20 for $\% 20$ the $\% 2021$ st $\% 20$ Century_FINAL.pdf

Westheimer, J. (2018). Fatal distraction: Audit culture and accountability in the corporate university. In M. Spooner \& J. McNinch (Eds.), Dissident knowledge in higher education (pp. 217-234). University of Regina Press.

York University. (2020). Mission and vision.York University. https://www.yorku.ca/about/missionand-vision/

Dr. Katherine (Katie) Crossman earned her Ph.D. in Teaching English as a Second Language from the University of Calgary in 2014. She has lived and worked in Canada, Mexico, and Russia. Katie has taught language and education courses at the post-secondary level for over a decade and works as an instructor with a focus on academic research at Bow Valley College. Her research interests centre around language and settlement.

Open Access This chapter is licensed under the terms of the Creative Commons Attribution 4.0 International License (http://creativecommons.org/licenses/by/4.0/), which permits use, sharing, adaptation, distribution and reproduction in any medium or format, as long as you give appropriate credit to the original author(s) and the source, provide a link to the Creative Commons license and indicate if changes were made.

The images or other third party material in this chapter are included in the chapter's Creative Commons license, unless indicated otherwise in a credit line to the material. If material is not included in the chapter's Creative Commons license and your intended use is not permitted by statutory regulation or exceeds the permitted use, you will need to obtain permission directly from the copyright holder.

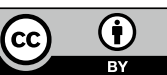

